\title{
Análise de crescimento do amarílis cultivado a pleno sol ${ }^{1}$
}

\author{
Caroline de Moura D’Andréa Mateus², Kathia Fernandes Lopes Pivetta ${ }^{3}$, Roberto Lyra Villas Bôas ${ }^{4}$, Ruchele \\ Marchiori Coan ${ }^{5}$
}

\section{RESUMO}

O cultivo de amarílis (Hippeastrum x hybridum Hort.) visa, principalmente, à produção e comercialização de bulbos para exportação. Informações sobre o seu ciclo de crescimento ainda são incongruentes. Assim, foi objetivo realizar medições que possam contribuir com estudos de análise de crescimento do amarílis var. Orange Souvereign, cultivado a pleno sol, nas condições encontradas em Santo Antônio de Posse, Estado de São Paulo. O delineamento experimental empregado foi o inteiramente casualizado. Utilizaram-se plantas cultivadas em uma área de 2 ha, onde os dados foram coletados mensalmente, durante 14 meses, de forma aleatória. Para cada uma das características analisadas foram utilizadas quatro repetições de 10 plantas. Aárea foliar determinada ao final do experimento foi de, em média, 3.102,65 $\mathrm{cm}^{2}$, tendo em vista 10 folhas por planta. O diâmetro do bulbo aumentou, gradualmente, durante todo o período de produção, finalizando aos 420 dias após plantio, com 9,15 cm em média. A massa fresca total ao final do ciclo foi de, em média, 1.050,55 g, dos quais 39\% (410 g) foram de massa fresca obtida pelo bulbo da forma como é comercializado (bulbo + raízes). Os índices fisiológicos da análise de crescimento (taxa de crescimento absoluto, taxa de crescimento relativo, taxa de assimilação líquida e razão de área foliar) demonstraram o comportamento da planta no campo, tendo o sistema assimilatório atingido bom desempenho nas condições de cultivo. O crescimento de amarílis foi considerado satisfatório do ponto de vista comercial.

Palavras-chave: Hippeastrum x hybridum Hort., floricultura, plantas ornamentais, índices fisiológicos.

\section{ABSTRACT}

\section{Growth analysis of amaryllis (Hippeastrum $x$ hybridum Hort.) grown in full sun}

Cultivation of amaryllis (Hippeastrum X hybridum Hort.) is mainly intended for production and commercialization of bulbs for export. Information on amaryllis growth cycle is still inconsistent, therefore this study was carried out to gather data that will contribute to studies on growth analysis of amaryllis var. Orange Souvereign in full sun. The experiment was arranged in a complete randomized design, with 4 repetitions and 10 plants per repetition for each analyzed characteristic. Plants were grown in an area of 2 ha and data were collected monthly over a 14 month period. The leaf area determined at the end of the experiment was on average $3102.65 \mathrm{~cm}^{2}$, considering 10 leaves per plant. Bulb diameter increased gradually throughout the period of production, ending, at 420 days after planting, with $9.15 \mathrm{~cm}$ on average. Total fresh mass at the end of the cycle was on average $1050.55 \mathrm{~g}$, of which $39 \%$ consisted of bulb fresh mass,

\footnotetext{
Recebido para publicação em março de 2008 e aprovado em junho de 2010 'Parte da Dissertação de Mestrado da primeira autora.

${ }^{2}$ Engenheira-Agrônoma, Mestre. Departamento de Produção Vegetal, Faculdade de Ciências Agronômicas e Veterinárias (FCAV), Universidade Estadual Paulista "Júlio de Mesquita Filho” (UNESP), via de Acesso Prof. Paulo Donato Castelane, s/n, 14870-900 Jaboticabal, São Paulo (SP), Brasil. caroline_mateus@hotmail.com

${ }^{3}$ Engenheira-Agrônoma, Doutora. Departamento de Produção Vegetal, FCAV, UNESP. kathia@fcav.unesp.br

${ }^{4}$ Engenheiro-Agrônomo, Doutor. Departamento de Recursos Naturais - Ciência do Solo, Faculdade de Ciências Agronômicas, UNESP, Rua José Barbosa de Barros, 1780, Faz.

Experimental Lageado, 18610-307, Botucatu, SP. rlvboas@fca.unesp.br

${ }^{5}$ Engenheira-Agrônoma, Doutora. Departamento de Produção Vegetal, FCAV, UNESP. ruchelecoan@hotmail.com
} 
which is the traded form (bulb +roots). The physiological indices of the growth analysis showed the plant behavior in the field, under the conditions found in Santo Antonio de Posse, São Paulo State, Brazil, with the assimilatory system having achieved a good performance in these growing conditions. Growth of amaryllis is considered satisfactory in this region, from the point of view of trading , as it can reach the standards required for export.

Key words: Floriculture, Hippeastrum X hybridum Hort., physiological indices, ornamental plants.

\section{INTRODUÇÃO}

A floricultura brasileira nos últimos anos vem se destacando como alternativa econômica viável e muito rentável de cultivo agrícola. Tal fato se evidencia pela exportação de produtos da floricultura que apresentam crescente desenvolvimento desde 1999. Nessa época, exportavamse apenas US\$ 13 milhões $(0,2 \%$ do mercado internacional). Em 2005, observou-se aumento de 20\%, atingindo patamares de US\$ 28 milhões (Kiyuna et al., 2005), e, em 2007, o faturamento com exportações chegou a cerca de US\$ 37 milhões (Junqueira \& Peetz, 2007).

Nos últimos anos, o interesse por flores bulbosas tem crescido significativamente e, como consequência, a área de cultivo dessas plantas tem aumentado em muitos países. Muitas delas são cultivadas em seu ambiente natural, geralmente em países tropicais e subtropicais (Rees, 1985).

Uma das maiores culturas de bulbo no mercado comercial advém do gênero Hippeastrum (Amaryllidaceae), tendo significativa importância na floricultura mundial. O amarílis (Hippeastrum x hybridum Hort.) é uma das plantas deste gênero e possui promissor futuro econômico (Tombolato, 2004).

Além de sua considerável beleza ornamental, o amarílis possui excepcional adaptação de cultivo no Brasil, visto que grande número de espécies é nativo no País e em todo o continente Sul-Americano. A maioria das espécies de Hippeastrum é endêmica da grande Bacia Amazônica, considerada o centro de dispersão do gênero (Tombolato \& Matthes, 1998; Tombolato, 2004).

Em amarílis, o período de dormência tem duração de aproximadamente três ou quatro meses. As folhas e flores ocorrem em estações separadas, as plantas possuem um órgão de reserva perene e o curso dos eventos é caracterizado por crescimento, armazenamento, dormência e florescimento. Há nessa espécie completa separação entre as fases de produção e armazenamento de assimilados, e as reservas necessárias para o processo de florescimento são acumuladas no ano anterior. Quando as reservas são insuficientes, o florescimento não ocorre no ano seguinte e são mobilizadas para o crescimento do aparelho fotossintético. O florescimento é completamente dependente do nível de armazenamento alcançado no fim do ano anterior e não das condições ambientais presentes no momento (Tombolato, 2004). Assim, é de suma importância para a cultura que os bulbos sejam bem produzidos para que o florescimento ocorra de forma adequada e com qualidade.

No Brasil, o volume de produção de bulbos de amarílis chega a mais de 3 milhões anuais, concentrados na região de Holambra, no Estado de São Paulo, basicamente destinada à exportação para a Holanda, com apenas pequena parcela comercializada no mercado interno (Tombolato, 2004). A comercialização mundial de amarílis tem se realizado na forma de plantas envasadas para uso em interiores e como bulbos induzidos ao florescimento, compondo maciços florais em jardins ou bordaduras ou até mesmo como flor de corte (Tombolato et al., 2001).

O consumo de flores no Brasil concentra-se nas datas especiais. Um estudo realizado por Mielke \& Cuquel (2004) demonstrou dois principais motivos que limitam o consumo do brasileiro: falta de hábito e alto preço para adquirir tais produtos.

Uma das possibilidades de se reduzir o preço desse produto e torná-lo mais atraente ao consumidor é a redução do custo de produção, por meio da otimização das unidades produtivas com o uso de tecnologia adequada. Esse procedimento pode conferir eficiência à área, aumentando a qualidade e quantidade do produto e, dessa forma, possibilitando a oferta de um produto a menor preço, estimulando assim o hábito de consumo.

A análise de crescimento é o primeiro passo a ser dado para o conhecimento de uma nova planta. Segundo Nogueira (1994), ela é o suporte na avaliação da produção primária, pois quantifica os componentes de crescimento. Dessa forma, para avaliar os efeitos de sistemas de manejo sobre as plantas a análise de crescimento é fundamental, pois descreve as mudanças na produção vegetal em razão do tempo, o que não é possível com o simples registro do rendimento. Segundo Magalhães (1986), a análise de crescimento serve, entre outras coisas, para se conhecerem os efeitos de sistemas de manejo e a adaptação ecológica das plantas a novos ambientes. 
Os princípios e práticas da análise de crescimento têm como objetivo descrever e interpretar o desempenho das espécies produzidas em ambiente natural ou controlado (Hunt, 1990). A análise de crescimento expressa as condições morfofisiológicas da planta e avalia sua produção líquida, derivada do processo fotossintético, resultado do desempenho do sistema assimilatório durante certo período de tempo (Benincasa, 2003).

Diante do exposto, objetivou-se estudar o comportamento fisiológico de crescimento do amarílis var. Orange Souvereign sob cultivo em solo a pleno sol, nas condições encontradas em Santo Antônio de Posse, Estado de São Paulo, Brasil. Buscou-se obter subsídios aos estudos dos fatores de produção, para aumentar a eficiência da produção de bulbos dessa espécie.

\section{MATERIAL E MÉTODOS}

O experimento foi conduzido no campo de produção de bulbos para exportação, a pleno sol, na Fazenda Terra Viva (Grupo Schoenmaker), localizada no município de Santo Antônio de Posse, SP. O clima da região é caracterizado por verão quente e estação seca nos meses de maio a setembro, com apenas $26 \%$ da precipitação anual (Embrapa, 2006).

Os tratamentos consistiram do período de avaliação ao longo do ensaio, ou seja, 14 meses (março de 2006 a abril de 2007). O delineamento experimental foi o inteiramente casualizado. As amostras foram coletadas de forma aleatória, mensalmente, em uma área total de dois hectares, quatro repetições de 10 plantas.

Em março de 2006, foram plantadas mudas de amarílis (Hippeastrum x hybridum Hort.), variedade Orange Souvereign, cujas flores são de coloração vermelha, uma das principais variedades plantadas visando à exportação dos bulbos. O cultivo foi conduzido a pleno sol, utilizando-se 40 mudas $/ \mathrm{m}^{2}$. O preparo das mudas foi feito pelo método de escamas duplas (twin scaling) (Tombolato, 2004).

A calagem foi realizada de acordo com análise química inicial do solo, utilizando-se calcário dolomítico, procurando elevar a saturação por bases (V\%) para 75\%. A adubação foi realizada antes da instalação do experimento e no seu decorrer, tanto por meio da adubação de cobertura (convencional) como por fertirrigação e via foliar (pulverização).

Foram realizados os tratos culturais necessários para o estabelecimento da cultura durante todo o seu ciclo, como a cobertura do solo com material orgânico (bagaço de cana) e controle de plantas invasoras. Fez-se o controle fitossanitário preventivo à base de produtos e doses adequadas à cultura. Foi realizada a aplicação de água por aspersão.
O crescimento da cultura foi avaliado a partir das seguintes características: a) número de folhas; b) área foliar $\left(\mathrm{cm}^{2}\right)$ : com medidor de área foliar eletrônico (Li-Cor, modelo L1-3100 $\left.{ }^{\circledR}\right)$; c) altura do bulbo $(\mathrm{cm})$ : com régua graduada; d) diâmetro do bulbo (cm): com paquímetro digital (Digimess ${ }^{\circledR}$, amplitude 0,01mm-300mm); e) massa fresca (g) das folhas, do bulbo + raízes e da planta total (folhas + bulbo + raízes): material lavado, separado e pesado em balança digital (precisão 0,01g); e f) massa seca (g) das folhas, do bulbo + raízes e da planta total: material acondicionado em sacos de papel e submetido à secagem em estufa com circulação forçada de ar a $70^{\circ} \mathrm{C}$, por 72 horas, e pesado em balança digital (precisão 0,01g).

A área foliar e a massa seca de lâminas foliares e totais das plantas foram ajustadas em relação ao tempo segundo a equação exponencial quadrática para se proceder à estimativa dos índices fisiológicos: taxa de crescimento absoluto (TCA), taxa de crescimento relativo (TCR), taxa de assimilação líquida (TAL) e razão de área foliar (RAF) pelo programa computacional ANACRES, segundo Portes \& Castro Júnior (1991). Assim, foram avaliadas as variáveis abaixo registradas:

a) Taxa de crescimento absoluto (TCA), em g mês ${ }^{-1}$ (expressão 1).

$$
T C A=\frac{M S T_{2}-M S T_{1}}{t_{2}-t_{1}}
$$

em que: $\mathrm{MST}_{2}$ é a massa seca total da parte aérea atual (g); $\mathrm{MST}_{1}$ é a massa seca total da parte aérea inicial (g); e $\mathrm{t}_{2}-\mathrm{t}_{1}$ é o intervalo de tempo entre duas coletas (meses).

b) Taxa de crescimento relativo (TCR), em g g$^{-1}$ por mês (expressão 2).

$$
T C R=\frac{\ln M S T_{2}-\ln M S T_{1}}{t_{2}-t_{1}}
$$

Em que: ln é o logaritmo neperiano.

c) Taxa de assimilação líquida (TAL), em $\mathrm{g} \mathrm{cm}^{-2}$ por mês (expressão 3).

$$
T A L=\left(\frac{M S T_{2}-M S T_{1}}{t_{2}-t_{1}}\right)\left(\frac{\ln A F_{2}-\ln A F_{1}}{A F_{2}-A F_{1}}\right)
$$

em que: $\mathrm{AF}_{2}$ é a área foliar total atual da parte aérea $\left(\mathrm{cm}^{2}\right)$; e $\mathrm{AF}_{1}$ é a área foliar total inicial da parte aérea $\left(\mathrm{cm}^{2}\right)$.

d) Razão de área foliar (RFA), em cm² g$^{-1}$ (expressão 4)

$$
R A F=\frac{A F}{M S T}
$$

em que: AF é a área foliar atual $\left(\mathrm{cm}^{2}\right)$; e MST é a massa seca total atual (g). 
Os resultados dos índices fisiológicos, derivadas, que compõem a análise de crescimento foram estimados pelo programa ANACRES, após ajuste da área foliar e massa seca em relação ao tempo, de acordo com as especificações de Portes \& Castro Júnior (1991).

\section{RESULTADOS E DISCUSSÃO}

Nas Tabelas 1 e 2 encontram-se os indicadores de crescimento utilizados no decorrer do ensaio.

As coletas foram realizadas apenas durante a fase vegetativa da planta. No presente ensaio, o amarílis foi produzido com a finalidade de comercialização do bulbo e não da flor de corte. Dessa forma, a planta não chegou ao florescimento. O bulbo de amarílis é perene, possui uma túnica formada por escamas externas, que secam e tornam-se membranosas. É constituído de uma parte inferior achatada chamada prato, no qual estão inseridas as escamas do bulbo, representando a base das folhas (Tombolato, 2004).

O número de folhas apresentou valor máximo de 12 entre 300 e 330 dias após plantio (DAP). Após essa época, ocorreu apenas a diminuição do número de folhas, ocasionada pela senescência e abscisão foliar, finalizando o ciclo de produção com cerca de 10 folhas por planta (Tabela 1). A área foliar alcançada ao final do experimento foi, em média, de $3.102,65 \mathrm{~cm}^{2}$ (Tabela 1).

A máxima altura do bulbo foi atingida ao final do ensaio, alcançando 9,33 cm (Tabela 1). Verificou-se aumento gradual no diâmetro do bulbo durante todo o período de produção, iniciando com $1,20 \mathrm{~cm}$, chegando à metade $(210$ DAP) com 3,40 cm e finalizando (aos 420 DAP) com 9,15 cm, em média (Tabela 1).

Tabela 1. Diâmetro do bulbo (DB), comprimento do bulbo (CB), número de folhas (NF) e área foliar (AF) de plantas de amarílis var. Orange Souvereign, cultivadas a pleno sol, em função da época de avaliação

\begin{tabular}{|c|c|c|c|c|}
\hline Idade & DB & CB & NF & AF \\
\hline dias & $\mathrm{cm}$ & $\mathrm{cm}$ & & $\mathrm{cm}^{2}$ \\
\hline 30 & 1,19 & 5,07 & 0 & 0,00 \\
\hline 60 & 1,38 & 5,69 & 1 & 16,25 \\
\hline 90 & 1,86 & 4,90 & 3 & 52,05 \\
\hline 120 & 2,31 & 6,10 & 4 & 95,29 \\
\hline 150 & 2,96 & 5,69 & 5 & 161,30 \\
\hline 180 & 3,15 & 6,08 & 6 & 260,01 \\
\hline 210 & 3,39 & 6,48 & 7 & 404,09 \\
\hline 240 & 4,24 & 6,59 & 9 & 786,37 \\
\hline 270 & 4,86 & 6,98 & 10 & $1.060,42$ \\
\hline 300 & 5,73 & 7,63 & 12 & $2.448,15$ \\
\hline 330 & 7,06 & 7,83 & 12 & $3.274,97$ \\
\hline 360 & 8,24 & 8,75 & 11 & $2.227,74$ \\
\hline 390 & 8,90 & 9,46 & 10 & $3.034,95$ \\
\hline 420 & 9,11 & 9,33 & 10 & $3.102,65$ \\
\hline
\end{tabular}

Ephrath et al. (2001) encontraram valores próximos para o diâmetro do bulbo, porém em condições controladas e aos 225 DAP. Com o controle da temperatura a $22^{\circ} \mathrm{C}$ foi obtido o diâmetro de $7,2 \mathrm{~cm}$, não diferindo estatisticamente da temperatura de $24^{\circ} \mathrm{C}(7,1 \mathrm{~cm})$. Utilizando-se diferentes tamanhos de bulbos iniciais, foi encontrado o maior diâmetro $(7,7 \mathrm{~cm})$ com o bulbo de menor tamanho inicial utilizado $(3,5 \mathrm{~cm})$. Valores diferentes nos índices de crescimento da cultura podem ser causados por diversos fatores, entre os quais variedade, densidade de plantio, manejo, condições ambientais.

A massa de matéria fresca total ao final do ciclo foi, em média, de 1.050,55 g, dos quais $61 \%$ foram de massa de matéria fresca de folhas e o restante, aproximadamente $410 \mathrm{~g}$, obtido pelo bulbo da forma como é comercializado (bulbo + raízes), como apresentado na Tabela 2. Ao longo do ciclo, houve contínuo acúmulo de massa de matéria seca do bulbo + raízes e da planta total, atingindo 44,74 e 85,47 g planta $^{-1}$, respectivamente, aos 420 DAP (Tabela 2). O bulbo + raízes foi o dreno principal da planta até os 210 DAP; durante os quatro meses seguintes o acúmulo de massa de matéria seca foi maior nas folhas, porém dos 360 aos 420 DAP o bulbo + raízes voltou a ter maior reserva de massa de matéria seca. Do total da massa de matéria seca produzida pela planta, 52,3\% foi do bulbo + raízes, que é a parte comercializada, e $47,7 \%$ da parte área, que volta para o solo no momento da colheita.

Pela comparação entre a massa de matéria seca das folhas e a massa de matéria seca do bulbo + raízes (Tabela 2) verificou-se que a primeira é maior até os 330 DAP, e a segunda torna-se maior aos 360, 390 e 420 DAP. Isso demonstra que o direcionamento do acúmulo de massa foi para as folhas até os 330 DAP e, após esse período, até os 420 DAP a massa foi direcionada para o bulbo + raízes, indicando acúmulo de reservas nele para posterior florescimento.

Os índices fisiológicos da análise de crescimento, TCA, TCR, TAL e RAF, estão apresentados nas Figuras 1 e 2. Estes índices, determinados na análise de crescimento, indicam a capacidade do sistema assimilatório das plantas em sintetizar (fonte) e alocar a matéria orgânica nos diversos órgãos (drenos). Assim, dependem da fotossíntese, respiração e translocação de fotoassimilados dos sítios de fixação de carbono aos locais de utilização ou de armazenamento, onde ocorrem o crescimento e a diferenciação dos órgãos. Portanto, a análise de crescimento expressa as condições morfofisiológicas da planta e quantifica a produção líquida, derivada do processo fotossintético, sendo o resultado do desempenho do sistema assimilatório durante certo período de tempo. Esse desempenho é influenciado pelos fatores bióticos e abióticos à planta (Larcher, 1995). 
Tabela 2. Massa de matéria fresca e massa de matéria seca das folhas (MFF e MSF), massa de matéria fresca e massa de matéria seca do bulbo + raízes (MFBR e MSBR) e massa de matéria fresca e massa de matéria seca total (MFT e MST) de plantas de amarílis var. Orange Souvereign, cultivadas a pleno sol, em função da época de avaliação

\begin{tabular}{|c|c|c|c|c|c|c|c|c|c|c|}
\hline \multirow{2}{*}{$\begin{array}{l}\text { Idade } \\
\text { dias } \\
\end{array}$} & \multicolumn{2}{|c|}{ MFF } & \multicolumn{2}{|c|}{ MSF } & \multicolumn{2}{|c|}{ MFBR } & \multicolumn{2}{|c|}{ MSBR } & \multirow{2}{*}{$\begin{array}{c}\text { MFT } \\
\mathrm{g} \\
\end{array}$} & \multirow{2}{*}{$\frac{\text { MST }}{\mathrm{g}}$} \\
\hline & $G$ & $\%$ & g & $\%$ & g & $\%$ & g & $\%$ & & \\
\hline 30 & 0,00 & 0 & 0,00 & 0 & 4,70 & 1,1 & 0,50 & 1,1 & 4,70 & 0,50 \\
\hline 60 & 1,70 & 0,3 & 0,11 & 0,3 & 5,96 & 1,4 & 0,45 & 1,0 & 7,65 & 0,56 \\
\hline 90 & 5,63 & 0,9 & 0,43 & 1,1 & 8,39 & 2,0 & 1,73 & 3,9 & 14,03 & 2,15 \\
\hline 120 & 11,57 & 1,8 & 0,89 & 2,2 & 15,41 & 3,8 & 1,27 & 2,8 & 26,98 & 2,16 \\
\hline 150 & 22,82 & 3,6 & 1,86 & 4,6 & 27,54 & 6,7 & 2,79 & 6,2 & 50,36 & 4,65 \\
\hline 180 & 39,57 & 6,2 & 2,80 & 6,9 & 34,50 & 8,4 & 3,34 & 7,5 & 74,07 & 6,14 \\
\hline 210 & 55,49 & 8,7 & 4,28 & 10,5 & 42,68 & 10,4 & 4,48 & 10,0 & 98,16 & 8,76 \\
\hline 240 & 131,93 & 20,6 & 8,88 & 21,8 & 69,96 & 17,1 & 7,13 & 15,9 & 201,89 & 16,02 \\
\hline 270 & 198,96 & 31,0 & 12,57 & 30,9 & 98,20 & 24,0 & 8,92 & 19,9 & 297,16 & 21,49 \\
\hline 300 & 343,13 & 53,5 & 18,54 & 45,5 & 139,62 & 34,1 & 12,52 & 28,0 & 482,74 & 31,06 \\
\hline 330 & 447,34 & 69,8 & 24,49 & 60,1 & 238,16 & 58,1 & 18,27 & 40,8 & 685,49 & 42,76 \\
\hline 360 & 532,08 & 83,0 & 31,98 & 78,5 & 333,92 & 81,5 & 35,16 & 78,6 & 866,00 & 67,14 \\
\hline 390 & 507,92 & 79,2 & 31,74 & 77,9 & 390,90 & 95,4 & 42,04 & 93,9 & 898,82 & 73,78 \\
\hline 420 & 640,84 & 100,0 & 40,72 & 100,0 & 409,72 & 100,0 & 44,75 & 100,0 & $1.050,55$ & 85,47 \\
\hline
\end{tabular}

A TCA pode ser utilizada para estimar a velocidade média de crescimento ao longo do ciclo da cultura ou do período de observação (Benincasa, 2003). Nota-se na Figura 1A, que há um crescimento vegetativo moderado até os 210 DAP, tornando-se ele mais acelerado após esse período e tendo seu pico aos 360 DAP, com cerca de 24,38 $\mathrm{g}$ mês $^{-1}$, valor esse quase três vezes superior à média do período (7,10 g mês $\left.{ }^{-1}\right)$. Segundo Bergamaschi et al. (1988), tal comportamento pode ser resultante de diversos mecanismos de respostas diretas e indiretas, como a absorção de nutrientes e alterações no mecanismo hormonal.

Outro índice fisiológico utilizado foi a TCR (Figura 1B), conhecido por taxa de crescimento específico, que representa a quantidade de material produzido por unidade de material já existente (Benincasa, 2003). Segundo Pereira \& Machado (1987), a TCR considera toda massa seca da planta como igualmente produtiva. De acordo com as observações registradas por Boaro (2001), verifica-se que a taxa de crescimento relativo apresentou efeito maior da taxa assimilatória líquida, mostrando comportamento muito mais semelhante a ela, do que a razão de área foliar, os dois índices que compõem a TCR.

A TAL representa o balanço entre o material produzido pela fotossíntese e o perdido por meio da respiração, expressando dessa forma a eficiência das folhas na produção de massa seca e a estimativa da fotossíntese líquida (Benincasa, 2003). Observa-se na Figura 2A, que a TAL no segundo mês (60 DAP) foi a mais elevada, provavelmente pelo fato de nesse estágio de desenvolvimento a planta apresentar ainda poucas folhas e não haver autossombreamento entre elas. Segundo Milthorpe \&
Moorby (1974), a TAL diminui com o aumento da área foliar devido ao sombreamento das folhas inferiores. $\mathrm{O}$ declínio acentuado durante o ciclo de desenvolvimento da cultura indica maior eficiência fotossintética, e esse
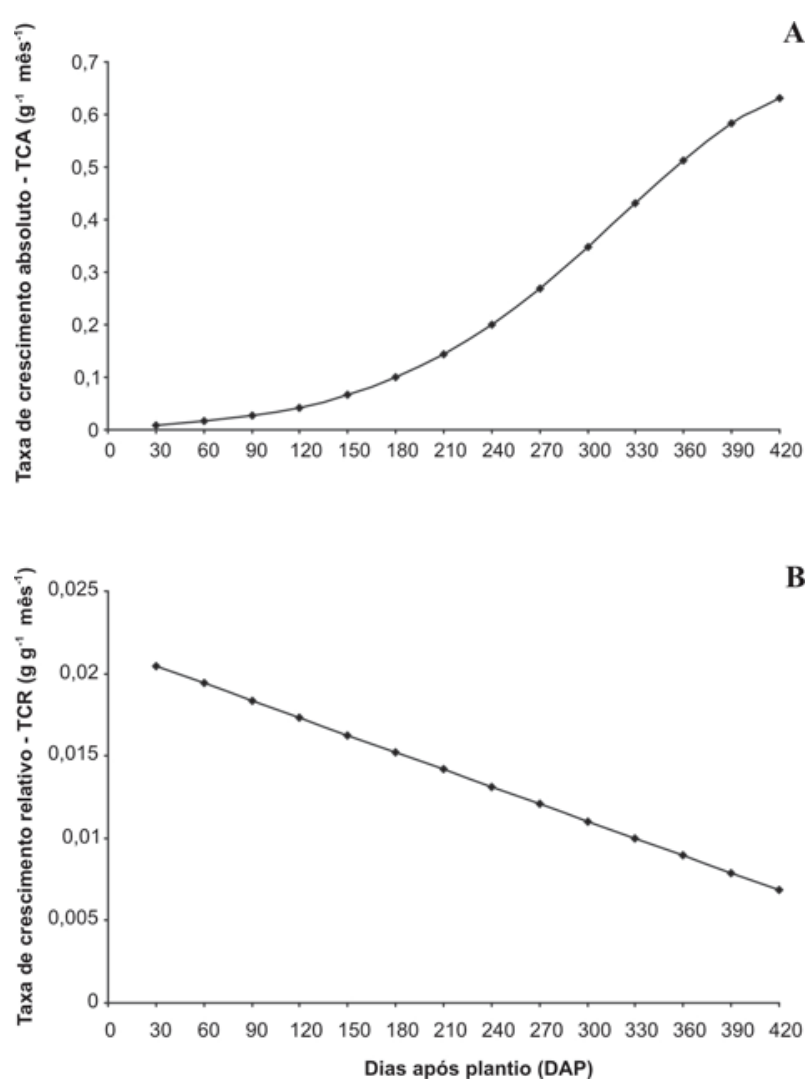

Figura 1. Taxa de crescimento absoluto (A) e taxa de crescimento relativo (B) de plantas de amarílis var. Orange Souvereign, cultivadas a pleno sol, em razão da época de avaliação. Valores ajustados pela equação exponencial quadrática. 
índice expressa a taxa de fotossíntese líquida, em termos de massa seca produzida (Portes \& Castro Júnior, 1991).

A RAF, segundo Benincasa (2003), expressa a área foliar útil para fotossíntese, razão entre a área foliar e massa seca total. De forma resumida, a RAF é a área foliar utilizada pela planta para produzir um grama de matéria seca (Benincasa, 2003). Os valores da RAF em função do tempo evidenciaram aumento até os 300 DAP e declínio acentuado a partir dessa idade até os 420 DAP (Figura 2B). Esses resultados são concordantes com os registrados na literatura para a RAF. No início do crescimento das plantas, segundo Urchei et al. (2000), a maior parte do material fotossintetizado é convertida em folhas, para maior captação da radiação solar disponível. A partir desse período, ocorrem decréscimos com o desenvolvimento fenológico da cultura, decorrentes do surgimento de tecidos e estruturas não-assimilatórias como os bulbos e as raízes, além do autossombreamento com a idade da planta. De acordo com Benincasa (2003), a RAF declina à medida que a planta cresce, devido ao aumento da interferência de folhas superiores sobre as folhas inferiores, gerando autossombreamento, e a tendência da área foliar útil é diminuir a partir de certa fase do desenvolvimento.
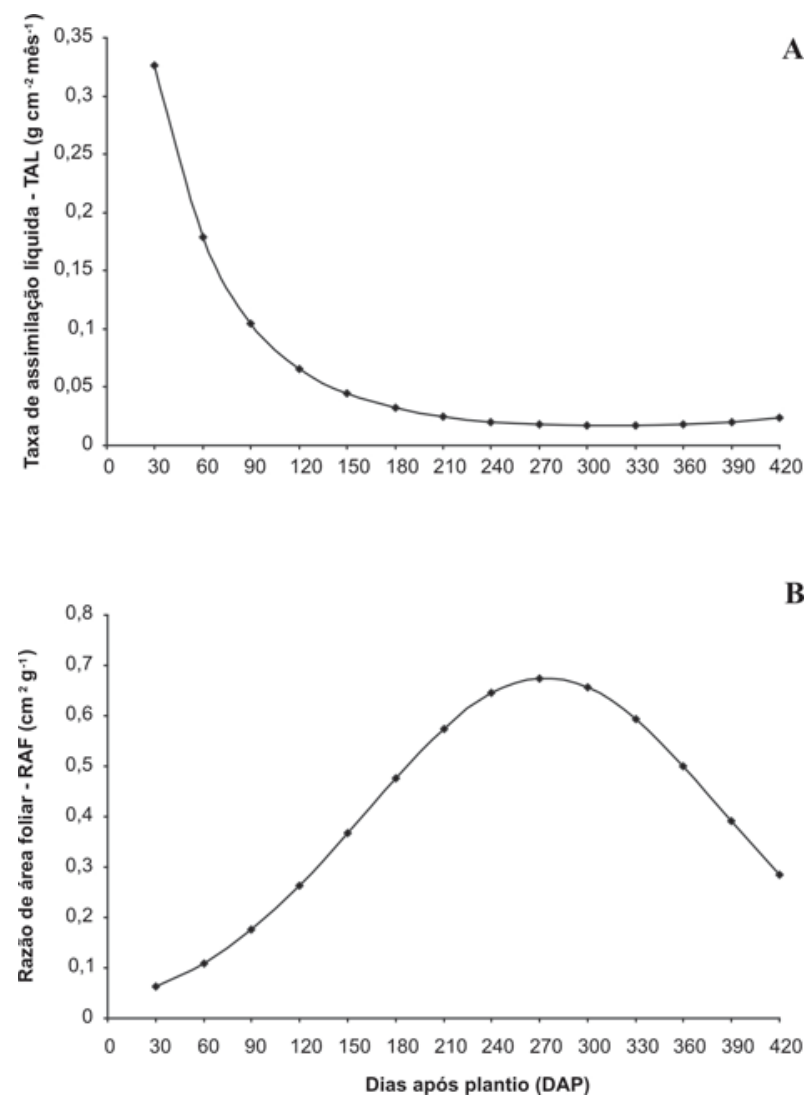

Figura 2. Taxa de assimilação líquida (A) e razão de área foliar (B) de plantas de amarílis var. Orange Souvereign, cultivadas a pleno sol, em razão da época de avaliação. Valores ajustados pela equação exponencial quadrática.

\section{CONCLUSÃO}

O amarílis var. Orange Souvereign demonstrou bom desempenho do cultivo nas condições estabelecidas em Santo Antônio de Posse, Estado de São Paulo.

\section{AGRADECIMENTO}

À Empresa Terra Viva (Grupo Schoenmaker), pelo apoio.

\section{REFERÊNCIAS}

Benincasa MMP (2003) Análise de crescimento de plantas (noções básicas). Jaboticabal, FUNEP. 41p.

Bergamaschi H, Vieira HJ, Ometto JC, Angelocci LR \& Libardi PL (1988) Deficiência hídrica em feijoeiro. I. Análise de crescimento e fenologia. Pesquisa Agropecuária Brasileira, 23:733743.

Boaro CSF (2001) Desenvolvimento de feijoeiros (Phaseolus vulgaris) em solução nutritiva com variação dos níveis de Mg e da relação entre macronutrientes, durante o ciclo. Tese de Livre Docência. Universidade Estadual Paulista "Júlio de Mesquita Filho”, Botucatu, 172p.

Embrapa - Empresa Brasileira de Pesquisa Agropecuária (2006) Disponível em: <http://www.jaguariuna.cnpm.embrapa.br/ localiza.html> Acessado em: 29 de novembro de 2006.

Ephrath JE, Ben-Asher J, Alekperovi CH, Silberbush M \& Dayan E (2001) The growth and development of Hippeastrum in response to temperature and $\mathrm{CO}_{2}$. Biotronics, 30:63-73.

Hunt R (1990) Basic growth analysis. London, Unwin Hyman. $112 p$.

Junqueira AH \& Peetz MS (2007) Exportações brasileiras de plantas e flores ornamentais: projeções indicam novo recorde para 2007. Disponível em: <www.hortica.com.br> Acessado em: 22 de julho de 2010.

Kiyuna I, Ângelo JA \& Coelho PJ (2005) Perspectivas no mercado interno. Agroanalysis, 25:26-27.

Larcher W (1995) Physiological plant ecology. Berlin, Springer. 448p.

Magalhães ACN (1986) Análise quantitativa de crescimento. In: Ferri MG (Ed.) Fisiologia vegetal. São Paulo, EDUSP, v.1. p.331350.

Mielke EC \& Cuquel FL (2004) Perfil do consumidor de rosa. In: Congresso Argentino de Floricultura y Plantas Ornamentales, Buenos Aires. Anais, INTA. p.287-290.

Milthorpe FL \& Moorby J (1974) An introduction to crop physiology. Grã-Bretanha, Cambridge University. 201p.

Nogueira SSS (1994) Growth analysis of chicpea (Cicer arietinum L.). Scientia Agricola, 51:430-435.

Pereira AR \& Machado EC (1987) Análise quantitativa do crescimento de comunidades vegetais. Campinas, Instituto Agronômico. 33p.

Portes TA \& Castro Júnior LG (1991) Análise de crescimento de plantas: um programa computacional auxiliar. Revista Brasileira de Fisiologia Vegetal, 3:53-60.

Rees AR (1985) Hippeastrum. In: Halevy AH (Ed.) Handbook of flowering. Boca Raton, CRC Press, v. l. p.294-296.

Tombolato AFC (2004) Cultivo comercial de plantas ornamentais. Campinas, Instituto Agronômico. 211p. 
Tombolato AFC, Costa AMM \& Eglit A (2001) Micropropagação de Hippeastrum hybridum 'Apple Blossom', mediante escamas duplas. Revista Brasileira Horticultura Ornamental, 7:35-40.

Tombolato AFC \& Matthes LAF (1998) Collection of Hippeastrum spp., Alstroemeria spp. and other Brazilian bulbous species. Acta Horticulturae, 454:91-98.
Urchei MA, Rodrigues JD \& Stone LF (2000) Análise de crescimento de duas variedades de feijoeiro sob irrigação, em plantio direto e preparo convencional. Pesquisa Agropecuária Brasileira, 35:497-506. 